\title{
A mature and fast-forming fibrous capsule using tetracycline: A preliminary report
}

\author{
Meltem Ayhan MD, Atilla Hacilar MD, Orgun Deren MD, Zeynep Aytug MD, Bülent Erdogan
}

\begin{abstract}
M Ayhan, A Hacilar, O Deren, Z Aytug, B Erdogan. A mature and fast-forming fibrous capsule using tetracycline: A preliminary report. Can J Plast Surg 2004;12(4):188-192.

The most frequently used method in two-stage reconstruction of a tendon is the placement of a silicone rod, forming a canal where the tendon can glide easily, that is subsequently replaced with a tendon graft. However, there is a disadvantage in that the formation of a qualified gliding canal requires at least three months after the placement of the silicone rod. In the present report, the authors evaluated the effects of tetracycline on the time period required for the formation of a qualified gliding canal in rats after the placement of a silicone rod. Tetracycline was administered through an 18 gauge needle inserted into the silicone rod in the test side (right) and saline solution was administered in the same fashion to the control side (left) in each rat. Histopathological and macroscopic examinations at weeks 1, 2, 3, 4 and 8 after the operation showed that a significantly thicker and more mature sheath was formed after two weeks in the sides that had been treated with tetracycline.
\end{abstract}

\section{Une capsule mature à formation rapide grâce à la tétracycline : Un rapport préliminaire}

La méthode la plus utilisée pour reconstruire un tendon en deux étapes consiste à installer une tige de silicone, formant un espace sur lequel le tendon peut glisser facilement, remplacé plus tard par une greffe de tendon. Cependant, il existe un inconvénient, car il faut au moins trois mois après l'installation de la tige de silicone pour qu'un espace de glissement acceptable se forme. Dans le présent rapport, les auteurs ont évalué les effets de la tétracycline sur la période nécessaire pour former un espace de glissement acceptable chez des rats après l'installation d'une tige de silicone. La tétracycline a été administrée au moyen d'une aiguille de calibre 18 insérée dans la tige de silicone du côté à l'essai (à droite), et une solution saline a été injectée de la même façon dans la tige témoin (à gauche) de chaque rat. Les examens histopathologique et macroscopique aux semaines 1, 2, 3, 4 et 8 après l'intervention ont révélé qu'au bout de deux semaines, une gaine beaucoup plus épaisse et plus mature s’était formée du côté traité à la tétracycline.

\section{Key Words: Fibrosis; Fibrous capsule; Silicone rod; Tetracycline}

$\mathrm{T}$ reatment outcomes are not always favourable in severe injuries of hand flexor tendons for many reasons, such as underlying fracture or overlying skin damage, fibrosis in the tendon bed or the development of infection during the recovery period. Therefore, these injuries are frequently treated with staged tendon reconstruction so that finger function can be regained. The mainstay of conventional staged tendon reconstruction is to first form a tunnel through which a tendon can glide easily, which is accomplished through the placement of a silicone graft. The second stage of the treatment is to replace the silicone graft with an autograft three months later (1-4). Shortening this three-month interval would result in an earlier return to daily activities. The effect of tetracycline on the time period required for the formation of a qualified canal in rats after placement of a silicone rod was evaluated.

\section{MATERIALS AND METHODS}

Six Sprague-Dawley rats were used, weighing between $250 \mathrm{~g}$ and $280 \mathrm{~g}$. The animals were caged individually at room temperature with a 12 h day/night (light/dark) cycle. Standard laboratory food and water were provided for the rats.
For the surgical procedures, the rats were anesthetized with an intraperitoneal injection of pentobarbital sodium $(50 \mathrm{mg} / \mathrm{kg})$. The body temperatures of the animals, measured with a rectal probe, were maintained between $35^{\circ} \mathrm{C}$ to $37^{\circ} \mathrm{C}$.

The backs of the rats were shaved. A $1.5 \mathrm{~mm}$ wide, vertical area of midline was stained and not dissected (Figure 1). A $1 \mathrm{~cm}$ incision was made on the right and left inferior sides of this line, and subcutaneous pouches wide enough for rod placement were formed in a cephalic direction. The left side of each rat was designated as the control side, and the right side was designated as the test side (Figure 2).

An 18 gauge needle was placed into a $4 \mathrm{~mm}$ diameter oval silicone rod (Silimed Inc, USA) (Figure 3). Using a needle, circumferential canals were formed in the silicone by drilling holes at $3 \mathrm{~mm}$ intervals in between and at $90^{\circ}$ angles to the gauge needle. The rods with gauge needles were then placed into the pouches created on the right side of each rat, leaving the reservoirs outside. During the operation, tetracycline $5 \mathrm{mg}(0.5 \mathrm{~mL})$ was injected into the silicone rod via the 18 gauge needle (Figure 3 ). The same procedure was performed on the left side of each rat, but $0.5 \mathrm{~mL}$ of saline solution was administered in place of tetracycline. The 18 gauge needles were inserted through the 


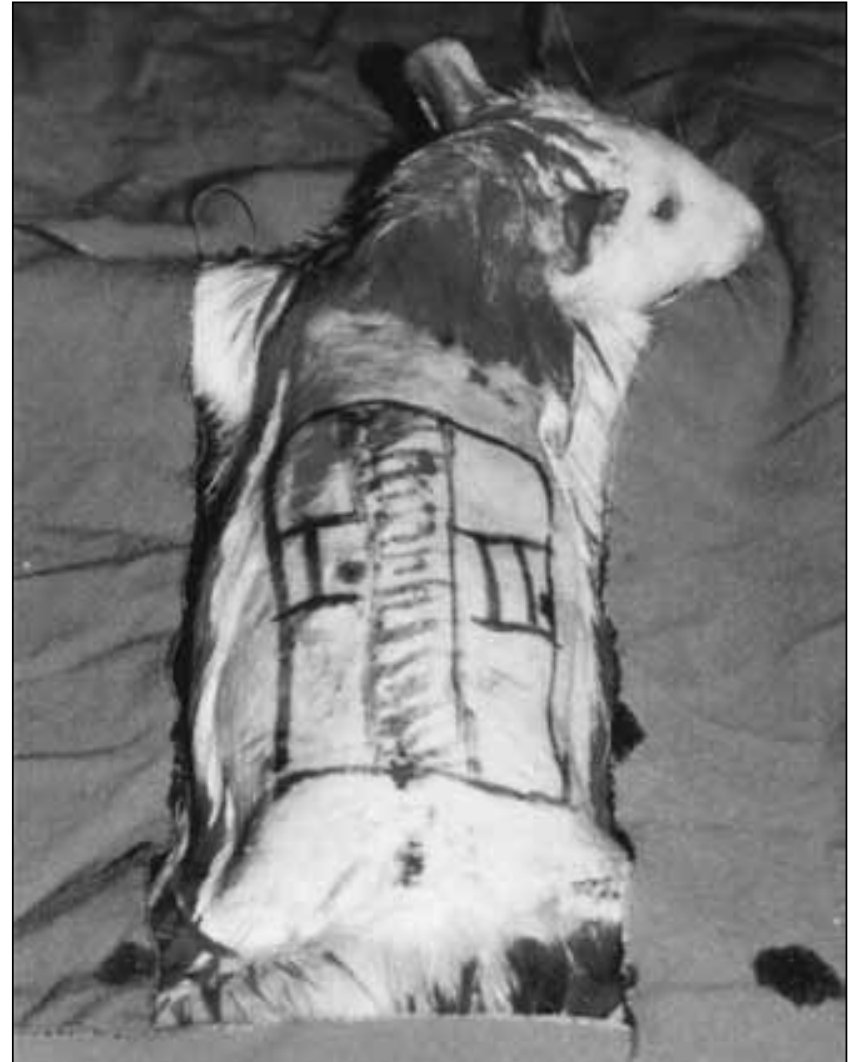

Figure 1) An example of the appearance of the backs of the rats and preoperative planning

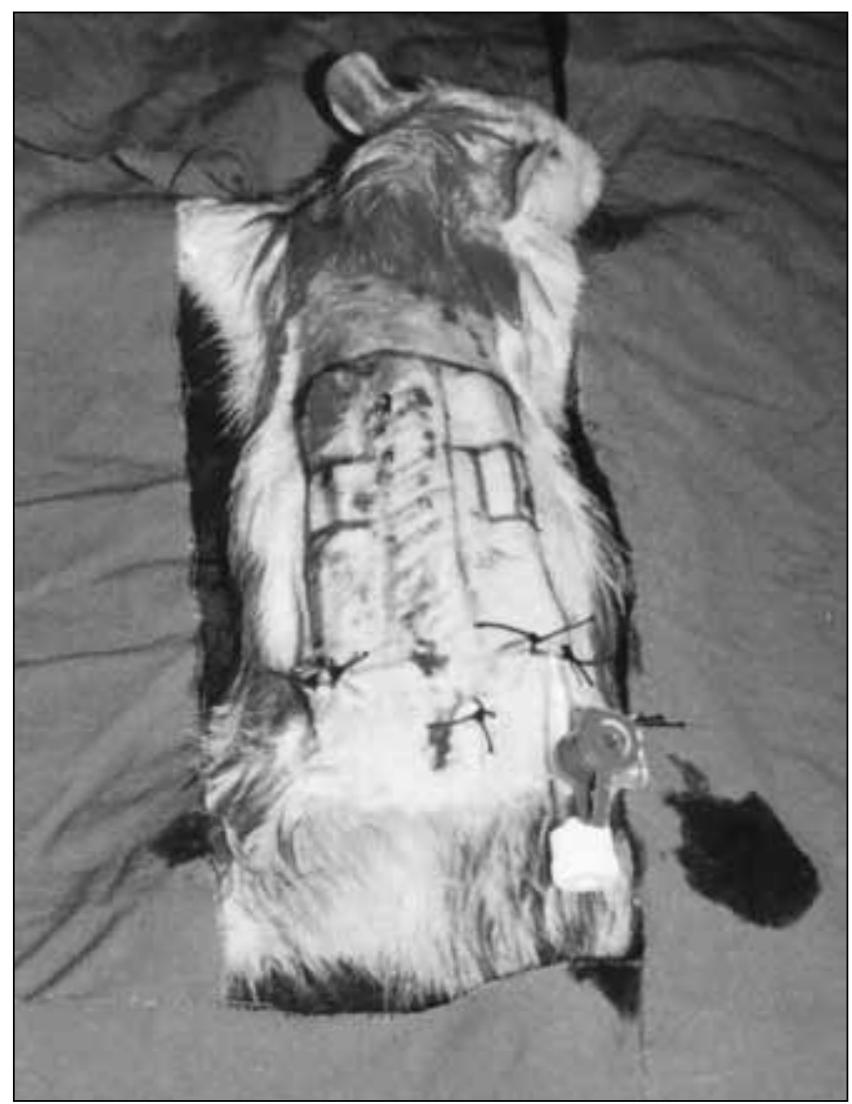

Figure 2) Placement of silicone rods with and without an 18 gauge needle into the backs of the rats

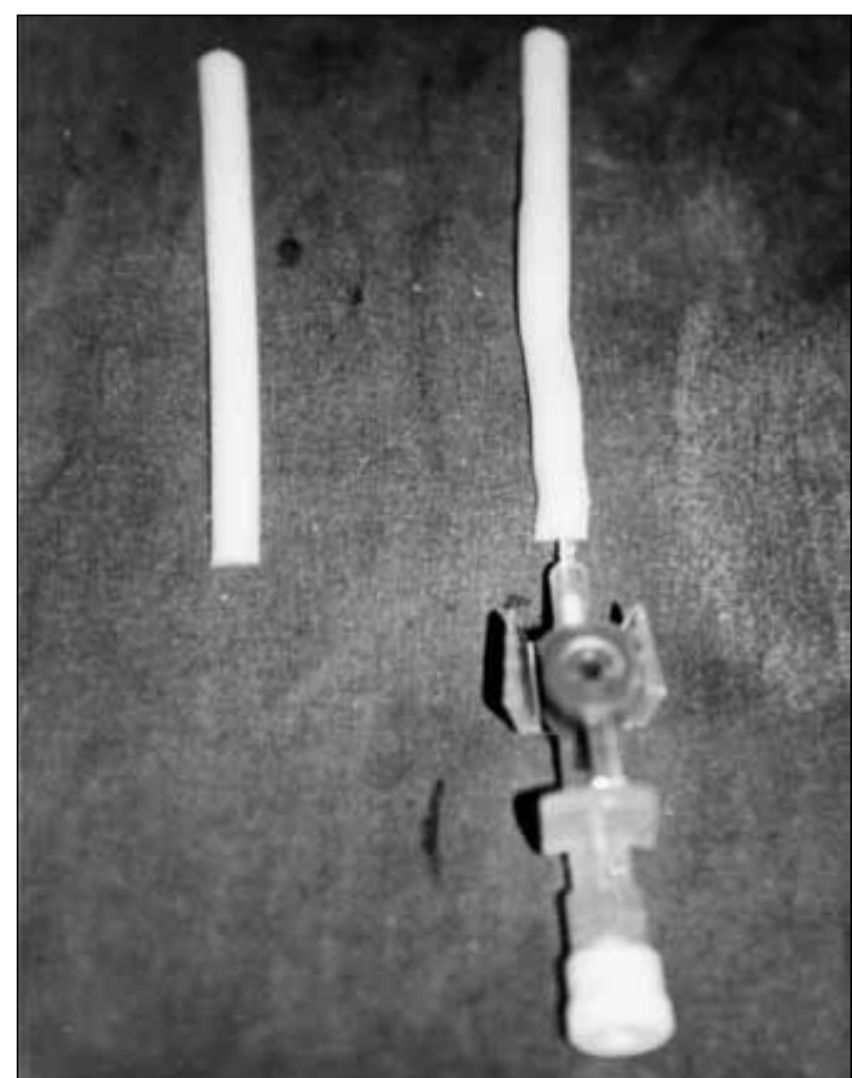

Figure 3) Silicone rod (left) and a silicone rod with the 18 gauge needle inserted (right)

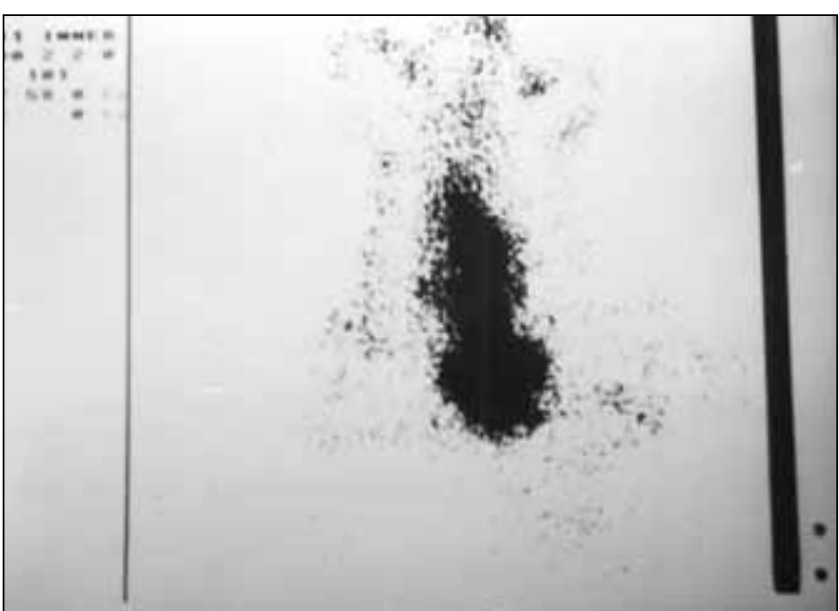

Figure 4) An example of a scan of a rat assessing the regularity of flow through the rod

rods and administered tetracycline into the rods so the tetracycline would leak, be distributed and form a more regular fibrosis where desired.

Five of the six rats were examined to assess the regularity of the flow through the rods. A silicone rod was placed in a subcutaneous pocket on the midline of the backs of these rats and $0.5 \mathrm{~mL}$ of $99 \mathrm{~m}$-technetium-pertechnetate $(50$ microcurie $)$ was injected through the rods using the same procedure. Images obtained by a SPECT Gamma camera (Nuclear Cardiology Systems, USA) showed that the tetracycline was delivered evenly (Figure 4). 
TABLE 1

Fibrosis thickness $(\mathrm{mm})$ in study and control sides at weeks 1, 2, 3, 4 and 8

\begin{tabular}{lcccccccccc}
\hline Subject & \multicolumn{2}{c}{ Week 1 } & \multicolumn{2}{c}{ Week 2 } & \multicolumn{2}{c}{ Week 3 } & \multicolumn{2}{c}{ Week 4 } & \multicolumn{2}{c}{ Week 8 } \\
Control & Test & Control & Test & Control & Test & Control & Test & Control & Test \\
\hline 1 & 15 & 25 & 20 & 32 & 25 & 35 & 30 & 45 & 32 & 44 \\
2 & 10 & 12 & 16 & 25 & 20 & 40 & 28 & 50 & 31 \\
3 & 15 & 15 & 21 & 30 & 25 & 35 & 35 & 43 & 35 \\
4 & 10 & 15 & 12 & 25 & 30 & 35 & 35 & 50 & 43 \\
5 & 15 & 15 & 20 & 30 & 25 & 35 & 30 & 43 & 48 \\
6 & 10 & 20 & 15 & 20 & 25 & 35 & 30 & 43 & 45 \\
\hline
\end{tabular}

TABLE 2

Statistical results (P values) of the Mann-Whitney $U$ test comparing the study and control sides

\begin{tabular}{lcccc}
\hline Week 1 & Week 2 & Week 3 & Week 4 & Week 8 \\
\hline 0.204 & $0.010^{*}$ & $0.002^{*}$ & $0.003^{*}$ & $0.003^{*}$ \\
NS & S & $S$ & $S$ & $S$ \\
\hline
\end{tabular}

${ }^{*} P<0.05(\alpha=0.05)$ compared with the control side at weeks 2, 3, 4 and 8 . NS Not significantly different; S Significantly different

At weeks 1, 2, 3, 4 and 8 after the operation, biopsies of the silicone rod and the capsule surrounding the silicone rod were obtained from both the test and control sides. Intact areas of $2 \mathrm{~cm}$ were left between the two consecutive biopsies. On histopathological examination, the diameter of the capsule forming around the silicone rod was measured and the surface of fibrosis facing the lumen was evaluated. Statistical analysis of the capsule thickness assessed at weeks 1, 2, 3, 4 and 8 was performed.

\section{RESULTS}

The thickness of fibrosis was determined on a light microscope (magnification of 40x; hematoxylin and eosin stain) in the biopsy materials taken at weeks 1, 2, 3, 4 and 8 after the operation from the test and the control sides. To convert the fibrosis thickness data (Table 1) to micrometres, the values can be multiplied by 0.025 . The data were left as they were for practical analysis.

The fibrosis thickness values obtained from the test sides were compared with those from the control sides using the Mann-Whitney $U$ test (an independent two-sample test). The results of statistical analysis are listed in Table 2 . The analysis showed a significant difference in fibrosis thickness between the control and test sides at weeks 2, 3, 4 and 8 .

The within group differences in fibrosis thickness among weeks 1, 2, 3, 4 and 8 were determined using the Friedman test (a dependent $\mathrm{k}$ sample test). The fibrosis thickness significantly increased at eight weeks $(\mathrm{P}=0.000086)$ in the control side. In the test side, fibrosis thickness increased significantly up to week 4; however, between weeks 4 and 8, no difference in fibrosis thickness was observed. In other words, there was no further increase in fibrosis thickness in the test side after week 4.

In the test side, histopathological examination showed that fibrosis was thicker (Figures 5, 6 and 7) and that the surface of the fibrosis facing the lumen was more regular from the second week on compared with the control side. From the fourth week on in the test side, collagen was observed to run parallel with the lumen and was arranged in a regular manner. This evaluation was made by two pathologists blinded to the study (Table 3). These findings show that fibrosis was more

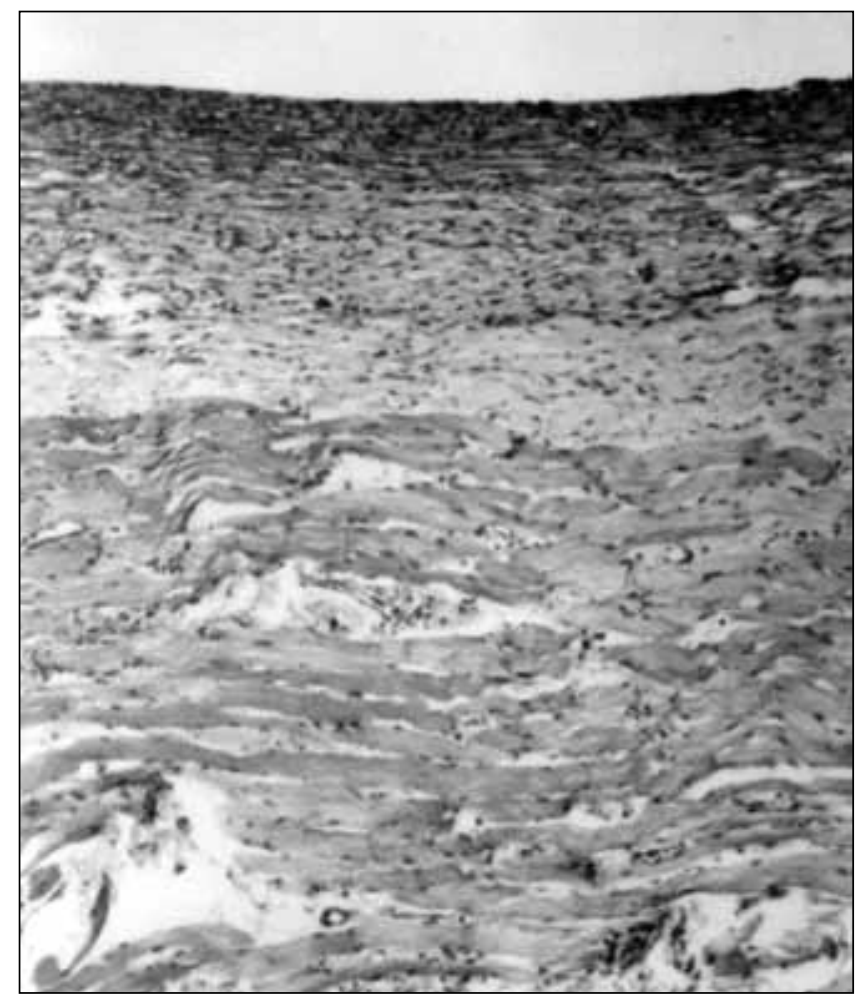

Figure 5) An example of the histopathological appearance in the control group at one week (hematoxylin and eosin stain, original magnification $\times 40$ )

mature in the test side than in the control side (Figure 8). In addition, palpation of the silicone rod revealed that it glided freely under the skin from the second week on in the test side.

\section{DISCUSSION}

The development of a fibrous capsule is often not a favourable condition in plastic surgery; however, in hand surgery, a mature and gliding fibrotic capsule is required for the formation of a tendon sheath. Throughout the numerous studies carried out with implants $(5,6)$, it has been observed that fibrous tissue formed around the implants within seven to 14 days and that the density of this tissue increased by the end of a two-month period. Hence, taking this all into consideration, we have tried to determine whether a mature and useful fibrous capsule can be formed. The reconstruction of serious flexor tendon injuries usually results in a poor outcome. In these injuries, the extent of the tendon function recovery depends on several factors, such as the location of the wound, the type of wound and the reconstruction technique used $(7-10)$. In serious and complicated situations, the retinacular system is often damaged and, 


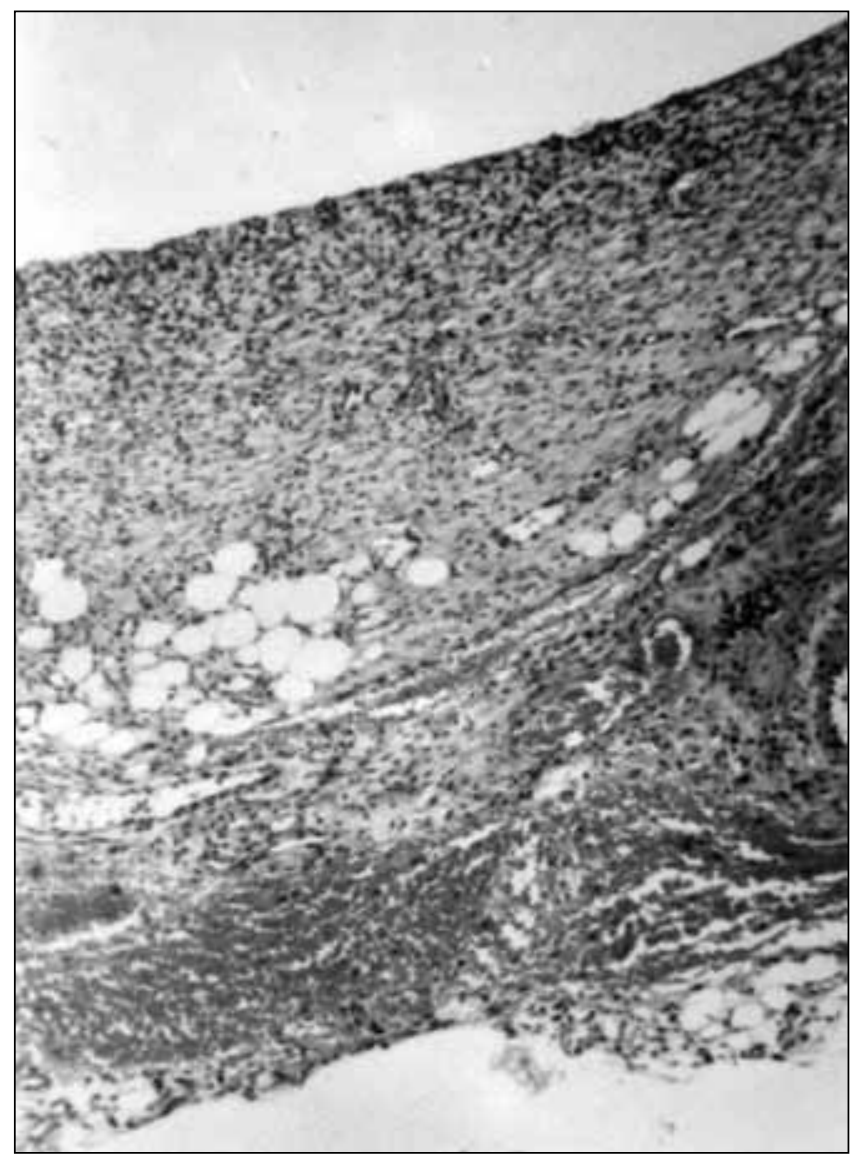

Figure 6) An example of the histopathological appearance in the test group at one week (hematoxylin and eosin stain, original magnification $\times 40$ )

because it heals with adhesions, loss of function is inevitable. The most successful technique that minimizes the loss of function is that which forms a smooth, mature fibrous sheath in which the tendon can easily glide and further its mechanical advantage. Many studies have investigated materials to determine which would best minimize the loss of function. In 1936, Mayer and Ransohoff (11), in their classical studies, used glass, metal and celloidin to form a false fibrous capsule. However, due to their lack of flexibility, these materials brought about some problems as well (11-13). In the 1960s, Carrol (14) tried to form a fibrous sheath using a flexible silicone rod. This method was later popularized by Hunter (15). In the 1970s, Hunter and Salisbury (2) reinforced the silicone rod with dacron.

In two-stage reconstruction, the implant is expected to form an even, soft and mature fibrous sheath in which the tendon can easily glide. Unfortunately, it takes at least three months to form a sheath of the desired thickness, as stated in the literature $(1,16-18)$. During this three-month period, patients cannot lead a normal life and, of importance, their quality of life declines. Is it possible to shorten this period to increase the life standard of the patients?

Tetracycline is used as a fibrosis-creating agent in the treatment of malignant pleural effusion (unpublished data). The fibrosis-creating effects of tetracycline have been investigated in experimental studies (19). Throughout these studies, it has been observed that tetracycline considerably increased the inflammation response, leading to fibrosis. Moreover, in

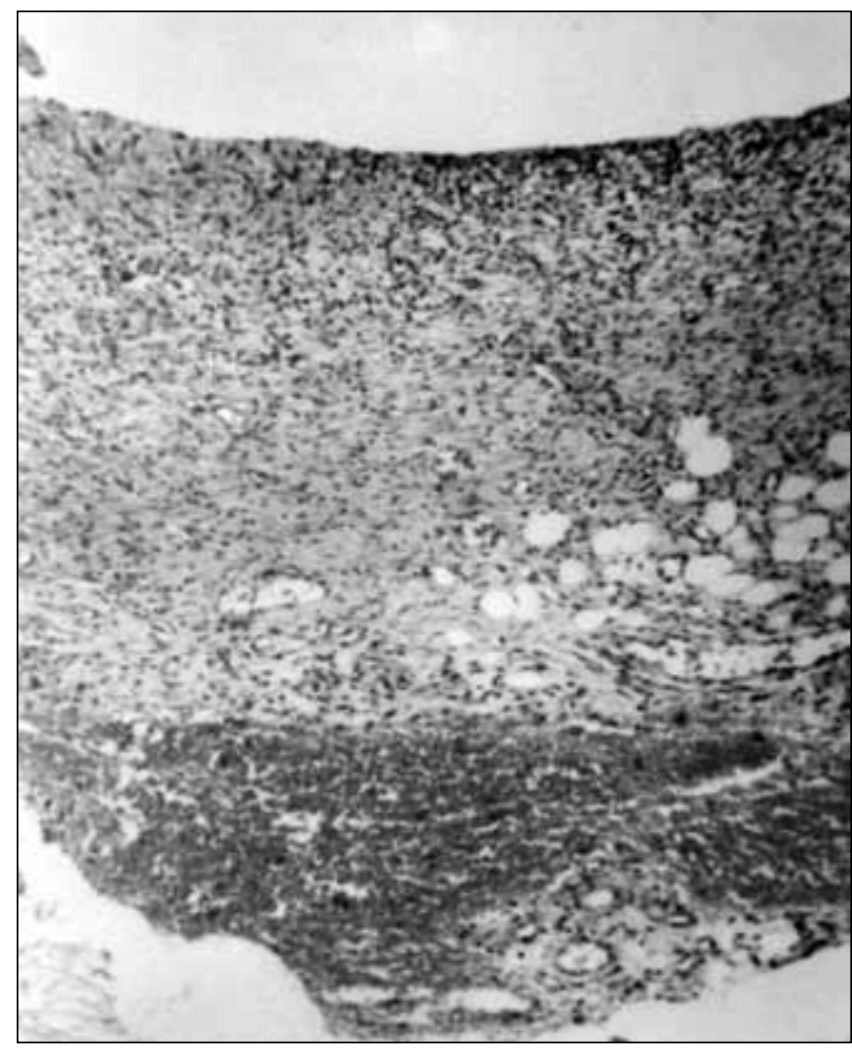

Figure 7) An example of the histopathological appearance in the control group at four weeks (hematoxylin and eosin stain, original magnification $\times 40$ )

TABLE 3

Regularity of the lumen on histopathological examination

\begin{tabular}{lcc}
\hline Week & Control side & Test side \\
\hline 1 & + & ++ \\
2 & + & ++ \\
3 & + & +++ \\
4 & ++ & +++ \\
8 & ++ & +++ \\
\hline
\end{tabular}

+ The surface facing the lumen is irregular; ++ The surface facing the lumen has minimal irregularities; +++ The surface facing the lumen is regular

further studies (20), it was shown that after a single dose, active tetracycline residue may be left in tissues for several weeks. This period seems to be an adequate amount of time to form fibrosis with a single dose.

In the present preliminary study, our aim was to produce a fibrous sheath faster and thicker than could be produced by the silicon rod alone, by giving a single dose of tetracycline. (The tetracycline was diluted with saline solution. By doing so, we eliminated any increase or decrease in fibrosis which may have arisen had it been diluted with other chemicals.) Based on the present results, we believe that we have achieved our aim. We confirmed, via a SPECT Gamma camera, that tetracycline, given through a silicone rod using an 18 gauge needle, spread slowly and effectively, with equal amounts leaking through the holes in the silicone. In comparison with the control side, the fibrosis was statistically greater around the silicone rod in the test side using the data from the histopathology and the biopsies taken at weeks 2, 3, 4 and 8 . 


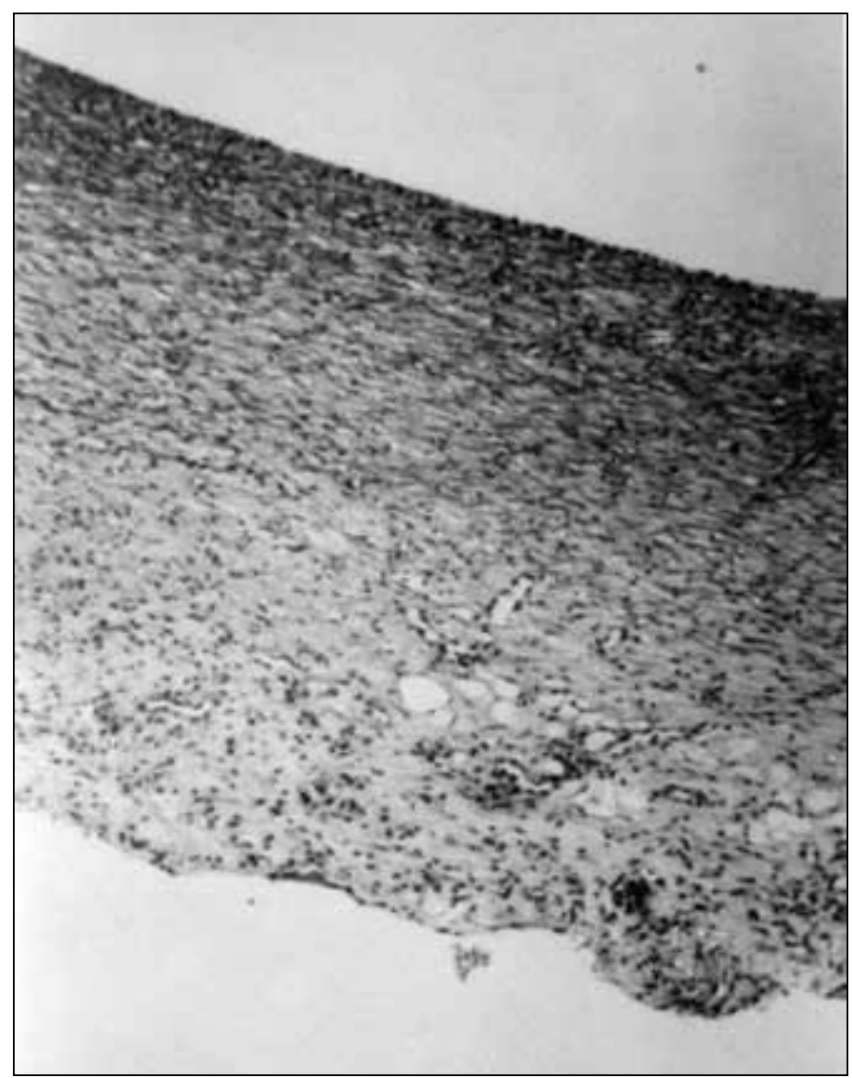

Figure 8) An example of the histopathological appearance in the test group at four weeks (hematoxylin and eosin stain, original magnification $\times 40$ )

To what extent did the fibrous sheath thickness tend to increase? According to the data from the present study, there was no increase in fibrous sheath thickness in the test side after week 4 . This result is advantageous because excessive fibrosis or an overly thick sheath are undesirable conditions. During week 2, fibrous sheath thickness in the test side reached the control side fibrous sheath thickness observed at week 8 . Although the thickness reached the desired level, this does not mean that maturation reached the maximum level as well. The adequacy of maturation was evaluated by two different pathologists blinded to the study conditions. According to their evaluations, it was determined that after week 2, the surface of the fibrous sheath was smoother and the collagen fibrils were parallel to each other in the test side. In other words, in the test side, the maturation of the fibrous sheath was complete from week 3 on. Furthermore, with palpation, the silicone rod in the test side glided easily through the subcutaneous tissue and no adhesion in the surrounding tissues was observed. When observed macroscopically, it was noted that the sheath formed in the test side did not differ extensively from the sheath in the control side. Taking all the data into consideration, we can conclude that tetracycline, applied together with the silicone rod, acclerates the fibrous sheath growth process and its maturation.

\section{CONCLUSION}

When tetracycline is applied in conjunction with a silicone rod, the fibrous sheath growth process and maturation are accelerated. Nevertheless, we believe that a study, such as the present investigation, should first be performed on animals in which tendon studies can be applied and in a tendon bed to be used in the formation of a tendon sheath.

\section{REFERENCES}

1. Gaisford JC, Hanna DC, Richardson GS. Tendon grafting: A suggested technique. Plast Reconstr Surg 1966;38:302-8.

2. Hunter JM, Salisbury RE. Use of gliding artificial implants to produce tendon sheaths. Techniques and results in children. Plast Reconstr Surg 1970;45:564-72.

3. Kleinert HE,Verdan C. Report of the Committee on Tendon Injuries. International Federation of Societies for Surgery of the Hand. J Hand Surg [Am] 1983;8:794-8.

4. Wehbe MA, Mawr B, Hunter JM, Schneider HL, Goodwyn BL. Two stage flexor tendon reconstruction. Ten-year experience. J Bone Joint Surg 1986;68:752-63.

5. Taylor SR, Gibbons DF. Effect of surface texture on the soft tissue response to polymer implants. J Biomed Mater Res 1983;17:205-27.

6. Thomson HG. The fate of the pseudosheath pocket around silicone implants. Plast Reconstr Surg 1973;51:667-71.

7. Farmer AW. Experiments in the use of cellophane as an aid in tendon surgery. Plast Reconstr Surg 1947;2:207-13.

8. Grau HR. The artificial tendon: An experimental study. Plast Reconstr Surg 1958;22:562-6.

9. Sarkin TL. The plastic replacement of severed flexor tendons of the fingers. Br J Surg 1956;44:232-40.

10. Weckesser EC. Technique of tendon repair. In: Flynn JE, ed. Hand Surgery, 2nd edn. Baltimore: Williams \& Wilkins, 1975:123-6.

11. Mayer L, Ransohoff N. Reconstruction of the digital tendon sheath: A contribution to the physiological method of repair of damaged finger tendons. J Bone Joint Surg 1936;18:607-16.

12. Mayer L. Celloidin tube reconstruction of extensor digitorum communis sheath. Bull Hosp Joint Dis 1940;1:39-45.

13. Thatcher HV. Use of stainless steel rods to canalize flexor tendon sheats. South Med J 1938;32:13-8.

14. Carroll RE. Formation of tendon sheath by silicone rod implant. Dow Corning Bull 1964;6:5.

15. Hunter J. Artificial tendons, early development and application. Am J Surg 1965;109:325-38.

16. Brug E, Stedfield HW. Experience with two-staged pedicled flexor tendon graft. Hand 1979;11:198-205.

17. Kessler FB. Use of pedicled tendon transfer with a silicone rod in complicated secondary flexor tendon repairs. Plast Reconstr Surg 1972;49:439-43.

18. Wehbe AM, Hunter JM. Flexor tendon gliding in the hand. Part II. Differential gliding. J Hand Surg [Am] 1985;10:475-9.

19. Good JT Jr, Taryle DA, Sahn SA. The pathogenesis of low glucose, low pH malignant effusions. Am Rev Respir Dis 1985;131:737-41.

20. Booth NH, McDonald LE, eds. Veterinary Pharmocology and Therapeutics, 6th edn. Iowa: Iowa State University Press, 1988. 